\title{
CLINICAL AND RADIOGRAPHIC OUTCOMES OF STRESS-FREE IMPLANT (SFI) BARS AND MILLED BARS FOR EARLY LOADED IMPLANT SUPPORTING MANDIBULAR OVERDENTURES. A ONE-YEAR RANDOMIZED TRIAL
}

\author{
Nasser Hussein Shaheen*
}

\begin{abstract}
Objectives: The aim of the present trial was to compare clinical and radiographic outcomes of stress-free implant (SFI) bars and Milled bars for early loaded implant supporting mandibular overdentures.

Materials and methods: Ten completely edentulous participants (6 males and 4 females) with sufficient bone anterior and posterior to the mental foramena received new maxillary and mandibular dentures. Patients were randomly allocated in 2 groups : group 1 include 5 patients who received milled bar overdentures, and group 2 include 5 patients who received SFI bar overdentures. Four implants were inserted according the flapless surgical protocol in canine and frist molar areas and early loaded by milled bar (group 1) or SFI bar (group2) 2 weeks after implant placement. Plaque and gingival indeces, pocket depth, fixture stability, and peri-implant bone resorption were measured at base line, 6 and 12 months after prostheis delivery.
\end{abstract}

Results: The survival rate was $95 \%$ and $100 \%$ for milled bar and SFI bar groups respectively. Plaque index and pocket depth significantly increased with passage of time for milled bar group only and SFI bar showed no difference in these parameters between observation times. Bone loss increased from 6 to 12 months significantly in both groups. No significant differences in gingival index and fixture stability between observation times or between groups were noted. Milled bar group showed significant higher plaque, pocket depth, and bone resorption than SFI bar group after 6 and 12 months.

Conclusion: Within the limitation of this randomized trial, it could be concluded that SFI bar is more advantageous for early loaded 4 implants supporting mandibular overdentures than milled bar as it was associated with decreased plaque accumulation, pocket depth and marginal bone resorption after one year.

* Associate Professor, Department of Removable Prosthodontics, College of Oral and Dental Surgery, Misr University for Science and Technology, Egypt. 


\section{INTRODUCTION}

The mainly implant-supported overdentures is positioned on 4 inter-foraminal implants, preferably interconnected with a triple bar. ${ }^{1}$ The implant supported overdentures have several advantages compared to the 2-implant retained overdentures such as; reduction of mucosal support ${ }^{2}$, excellent retention, good stabilization of the prosthesis, minimization of ridge resorption and elimination of denture rotation and posterior ridge loading ${ }^{3}$. The rigid anchoring of such prosthesis also provides stable occlusion, and reduces prosthodontic maintenance ${ }^{4}$. Furthermore, it improves bite force, chewing efficiency and muscle activity compared to 2 implant overdentures ${ }^{5}$. In contrast to fixed prosthesis, implant supported overdentures are cost effective, more hygienic, easy in maintenance. In addition it is suitable for patients with phoneticaesthetic problems such as loss of lip support, very long clinical crowns, abnormal arch relationship, and wide interproximal spaces ${ }^{6}$

For implant supported overdentures, implants are conventionally placed in the interforaminal area of the mandible as this location was reported with high implant success and survival rates ${ }^{7}$. However, placement of the implants in this region usually necessitate construction of distal cantilevers of the bar superstructure to make the overdentures fully supported and to provide the patient with good chewing capacity in molar regions ${ }^{8}$. These cantilevers transfer more stresses to the distal implants ${ }^{9}$ which may increase bone loss and jeopardize the integrity of these implants ${ }^{8}$. It also may increase incidence of prosthetic complications like fractures of cantilevers ${ }^{10}$. Moreover, the length of cantilevers may not be sufficient to extend support area posteriorly due to decreased A-P spread (distance from line pass through most distal implants perpendicular to the most anterior implant at midline $)^{11}$. Other alternative is to place the implants in canine and first molar area (posterior to the mental foramina) ${ }^{5,12-14}$. When these implants are connected with bar, they provided several merits such as; full implant support without the need of distal cantilevers, excellent prosthesis retention and stability, wide load distribution ${ }^{12,15}$, improved chewing ability and electromyographic muscle activity, and improved masticatory function ${ }^{5}$. Moreover, Shaarawy and Aboelross ${ }^{16}$ reported wide distribution of immediately loaded implants supporting mandibular overdentures by insertion of 2 implant fixtures behind the mental foramina and connection of the overdentures with implants with rigid telescopic attachments. They noted improved peri-implant bone density and increased activity of masseter and temporalis muscles.

The early loading of the implants involves application of functional occlusal load to an implant prosthesis between 2 weeks and 3 months after implant placement ${ }^{17}$. Early loading of implants with implant-overdentures, reduces time of final rehabilitation, increases patient satisfaction and early restore mastication and aesthetics ${ }^{18 .}$ Bar attachments offer several advantages compared to unsplinted attachments when used for immediate and early loading. Such advantages include load sharing between implants, reduction of lateral and torque forces $^{19,20}$, and increased lateral and horizontal stability $^{21}$. However, the disadvantages of bars include more complex laboratory procedures, lack of passive fit $^{22}$, the need of vertical restorative space $^{23}$, and the complicated oral hygiene procedure ${ }^{24}$. Milled bar overdentures are rigid, totally implant supported prosthesis that combines the advantages of fixed and removable prosthesis. Compared to fixed restoration, they are cost effectiveness, have reduced prosthetic complications ${ }^{14}$. The prosthesis can be removed to perform adequate oral hygiene and avoid deleterious effects of para functional habits ${ }^{25,26}$. Compared to other types of overdentures, milled bars have excellent retention and stability, prevent lateral and rotational movements, reduce prosthetic maintenance. In addition, denture flanges can be shortened to provide more patient comfort ${ }^{14}$. Stress free-implant bar is prefabricated round bar that allow chair-side adaption for immediate loading 
protocol ${ }^{27}$. This bar connects implants with no soldering or laser-welding. This allows construction of a passive-fit $\operatorname{bar}^{28}$ with reduced corrosion ${ }^{29}$. Moreover, this bar can be used with individual implant angulations up to $15^{\circ 30}$. It consists of 2 or 4 ball joints that are connected to implant adapters by screws and tube bar. Despite these several advantages, long-term success of this system still has to be proved in randomized clinical studies ${ }^{30}$ that compared it to the conventional used bars.

The aim of the present trial was to investigate clinical and radiographic results of stress-free implant bar and milled bars for implant supported early loaded mandibular overdentures after one year. The null hypothesis stated by the authors at the start of the study that will be no difference in these outcomes between the 2 types of bars.

\section{MATERIALS AND METHODS}

\section{Participant enrollement}

Ten completely edentulous participants (6 males and 4 females, mean age $=55.98 \pm 5.5$ years) who attend regularly at the clinic of prothodontic departement for sake of complete mouth rehabilitation were enrolled in the this clinical trial. The inclusion characters are; 1) all participants had no denture experience or unsatisfied by the retention of the mandibular dentures and wanted a more stable and retentive prothesis, 2) sufficient remaining bone in vertical height, and buccolingual thickness mesial and distal to the mental foramen to allow installation of standered diameter implants of at least $11 \mathrm{~mm}$. This was checked by Cone beam computerized radiography before implant insertion. 3) adequate amount of interarch space of at least $15 \mathrm{~mm}$ from the occlusal plane of the mandibular denture to the mucosa of the ridge. Exclusion characters include: Patients with advanced cardiovascular disease, liver dysfunction, blood dyscrasias or patients underwent anticoagulant therapy, diabetic patients, patients with osteoporosis or long-term radiation therapy, smokers, and inability to practice good oral hygiene. The patients instructed about the treatment protocol and objectives prior to obtain an informed consent. The study was conducted according the ethical principles of Helsinki Declaration (https:// www.wma.net/) and approved by the ethical committee of the faculty. New maxillary and mandibular dentures were made to all participants. The patients were asked to participate in this study without prior knowledge of which type of attachments they were going to receive. Patients were randomly allocated into 2 groups (5 patient/ group) using a simple randomization procedure (random generated numbers in Excel sheet) to ensure equal sex distribution in each group: Group 1 (G1) the overdentures were connected to the implants with milled bar attachments. Group 2 (G2) the overdentures were connected to the implants with SFI bar attachments. To reduce the risk of bias, comparison of base line criteria between groups was made to ensure that there was no significant difference between groups in age, gender, period of edentulism and mandibular alveolar bone height.

\section{Surgical and prosthetic procedures}

Radiopaque Gutta Perchae markers are added to the polished surface of the mandibular denture at labial, buccal and lingual flanges. Using cone beam CT (CBCT, i-CAT, Imaging Sciences International ISI, Pennsylvania, USA), the patients were scanned while wearing their maxillary and mandibular dentures, then the mandibular dentures were scanned alone. Overlapping of the images were made using 3-D image treatment planning software (OnDemand). According to the CT scan, the implants were virtually planned in canine and first molar areas of the mandible anterior and posterior to the mental foramen to achieve a quadrilateral implant distribution, then an individualized stereolithographic surgical guide was constructed using prototyping technique. Implants were planned parallel to each other's. A mucosal supported stereolithographic surgical template with 4 sleeves positioned over proposed implant 
sites was constructed using 3D printing technology (In2Guide).

Four implants (Neoss Ltd., Harrogate, England) were inserted according the flapless surgical protocol using the surgical guide and the universal surgical kit (In2Guide, Universal Kit Cybermed Inc) supplied with the mucosal supported stereolithographic surgical template to be used during osteotomy preparation (fig 1).

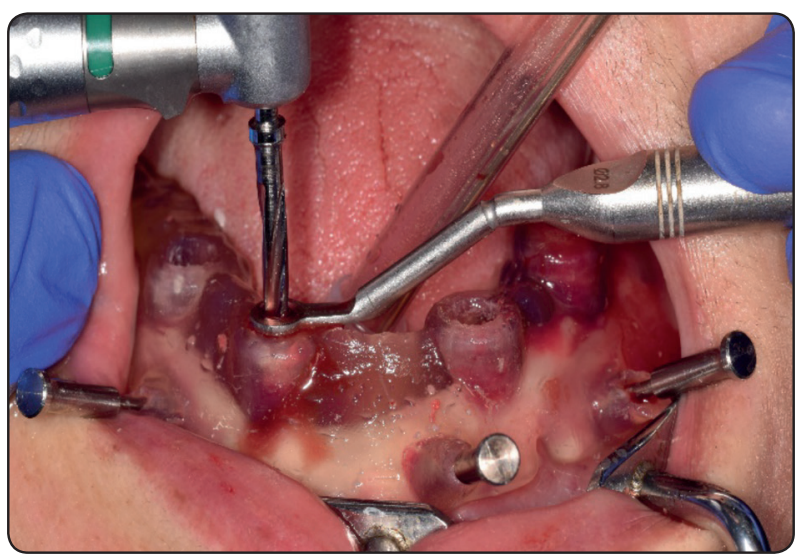

Fig. (1) Implant placement using the sterolitographic guide

Hand sleeves with increasing diameters that fit both long drills and template sleeves were used for osteotomy preparation. The guide was fixed in patient mouth using interocclusal record and fixation pins. The minimum torque at implant placement was $35 \mathrm{Ncm}$ to permit early loading of the implants ${ }^{31}$. Directly after implant insertion, open tray impression procedure was started. Custom acrylic tray was constructed with perforations on the implant positions. Long impression posts were threaded to the implants and splinted in patient mouth using a special resin with minimal dimensional changes (Duralay, Reliance Dental MFG Co, Worth, IL, USA) to prevent movement of the impression posts during impression removal. Light consistency rubber base impression was loaded around the impression posts and the overall impression was made using putty material (Zhermack ${ }^{\circledR}$, Badia Polesine, Rovigo, Italy). Implant analogues were attached to the impression posts and the impression was poured using hard stone. Healing abutments were connected immediately after implant placement. All patients received postoperative antibiotics (amoxicillin $625 \mathrm{mg}$ + clavulanic acid 125mg, Augmentin ${ }^{\circledR} 1 \mathrm{gm}$ ) for 6 days later. Corticosteroids (Dexamethazone ${ }^{\circledR}$ ) was given. Anti-inflammatory medication (ibuprofen ${ }^{\circledR}$, $600 \mathrm{mg}$ ) was administered for 4 days postoperatively. Analgesics (Ketolac ${ }^{\circledR} 10 \mathrm{mg}$ ) were given on the day of surgery and postoperatively for the first 4 days.

For milled bar group, bar abutments were screwed to the analogues on the cast, and plastic caps were screwed to bar abutments. The milled bar was constructed using resin pattern (Duralay, Reliance Dental MFG Co, Worth, IL, USA) with $5 \mathrm{~mm}$ vertical height and $4 \mathrm{~mm}$ buccolingual width. For oral hygiene purposes, $1-1.5 \mathrm{~mm}$ space was maintained below the bar. Hader bar segments were added to the top of the milled bar between the implants (OT bar multiuse ${ }^{\circledR}$, RHEIN 83, Italy). The resin bar was milled using manual milling machine (SR-20RIII, Star Micronics, Nakayoshida, Japan). After milling, the bar was cast in cobalt chromium alloy and refined by milling again using a bur that creates an occlusal taper of 4 degrees. The cast bar was tried intraorally to ensure passive fit using screw test. If the bar was not passive, sectioning and soldering was made. The bar was returned to the cast, and plastic clips were added to Hader bar segments. The housing of the milled bar was waxed over the cast bar, invested and cast in the same alloy (fig 2). The housing was tried in for passivity over the bar, and necessary relieve was made. Record bases were made and after registration of jaw relations, the bar was returned to the cast. The housing was fastened to the bar and packing of acrylic resin was made over the housing in the conventional manner.

For SFI bar group, adjustment of the bar was made on the cast to provide more accessibility and saving the time in the surgical appointment. The SFI-Bar ${ }^{\circledR}$ (Cendres + Metaux, Biel/Bienne, Switzerland) adapters (abutments) were threaded to the implant analogues. The ball joint of the bar was fixed to the 

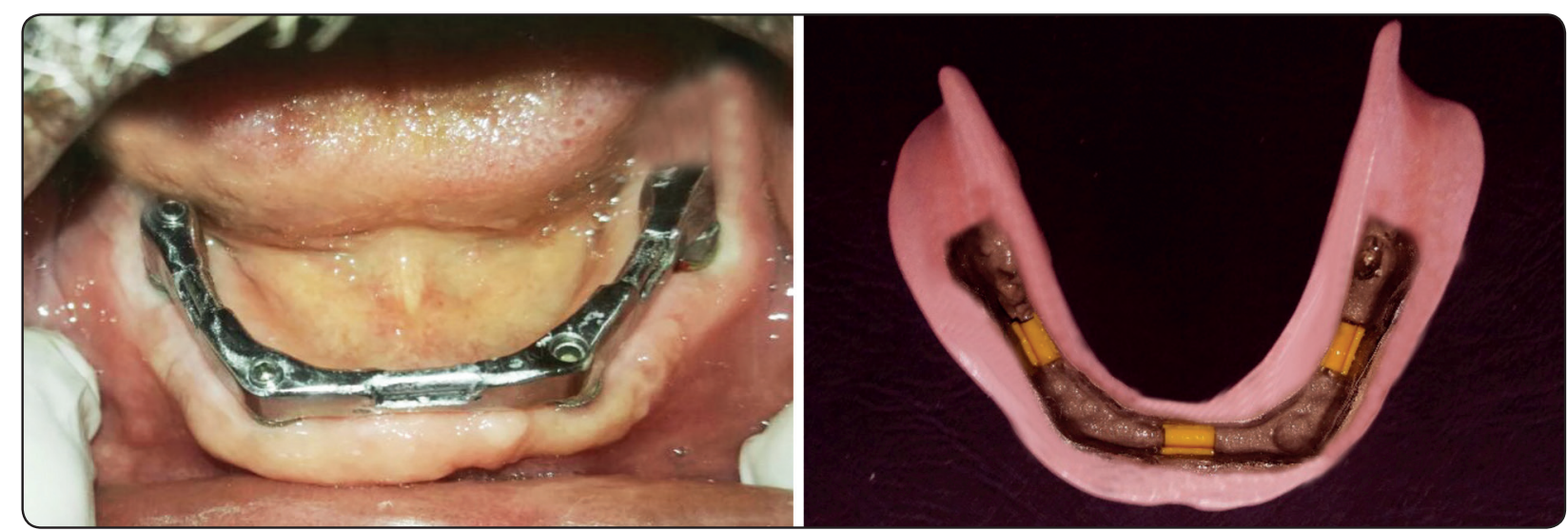

Fig. (2) Milled bar group: A; bar in place in patient mouth, B; fitting surface of the overdentures with clips in place

adapters, but the fixation screws were loosened to allow adjustment of the bar length. The tube bar gauge was attached to the bar and slide onto the pin of the ball joint until the joint can be fitted to the adapter and the retaining screws were retightened. The tube bar was sectioned and slide onto the pins of the ball joints and retightened tension-free. The procedure was repeated for the other 2 segments of the bar. Record bases were made and after registration of jaw relations, the bar was returned to the cast. The plastic clips with overlying housing were fastened to the bar segments, and packing and curing was completed in the usual manner (fig3).

For both groups' overdenture delivery was made 2 weeks after implant placement. Participants

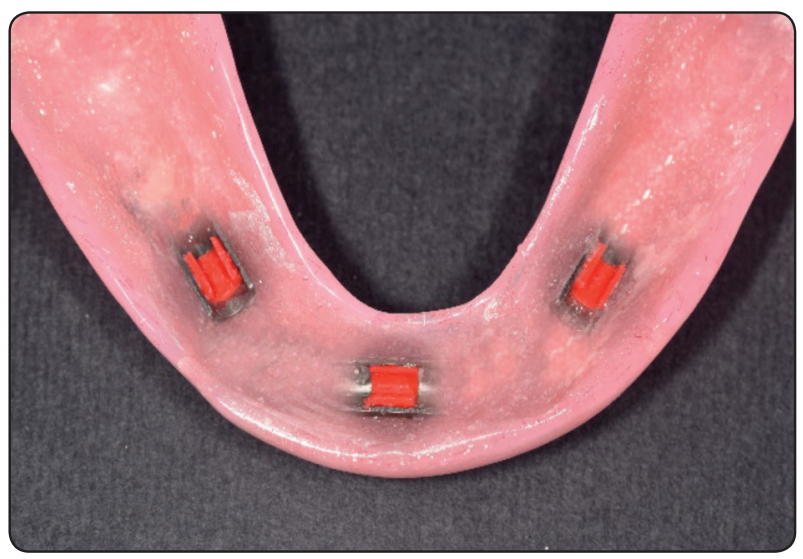

Fig. (3) SFI bar group, A; Adjustment of the bar on the cast. B; bar in place in patient mouth, $\mathrm{C}$; fitting surface of the overdentures with clips in place were informed to eat soft diet and avoid hard foods. Participants were instructed for oral hygiene procedures, and informed to attend regular followup visits to verify oral hygiene practice and perform adjustments of the relined dentures till osseointegration occurs.

\section{Implant related outcomes}

\section{A) Clinical outcomes}

The following parameters were recorded for each implant by the same examiner (SH.N) at time of overdenture insertion (T0), 6 (T6) and 12 (T12) months after overdenture insertion: Plaque index (PI) according to Mombelli et al. ${ }^{32}$ using the following scores: $0=$ no plaque detected, $1=$ plaque only recognized by running a probe across the surface supragingivally, 2 = plaque can be visually seen with unaided vision, $3=$ abundance of soft matter. Gingival index (GI) according to Loe and silness ${ }^{33}$ using the following scores: $0=$ no bleeding, $1=$ pinpoint bleeding, $2=$ linear bleeding, $3=$ profuse bleeding. Probing depth (PD): The distance between marginal border of the gingiva and the tip of a periodontal probe when placed in peri-implant gingival pocket was recorded as probing depth. PI, GI and PD recorded at midmesial, mid-labial, mid-distal and mid lingual aspects of each implant. Implant stability (ISQ): was measured by means of resonance frequency 
analysis (RFA, Osstell ${ }^{\mathrm{TM}}$; Osstell AB, Gothenburg, Sweden) and expressed with ISQ measurement scale (implant stability quotient) after attaching the implant-specific SmartPegs to the implant ${ }^{34,35}$. The measurements were performed on the patient level, ie, right and left measurements for canine and molar implants were averaged.

\section{B) Radiographic outcome}

For each participant, Cone beam computerized tomography (i-CAT device; Imaging Sciences Intl) was made at base line, 6 months $(6 \mathrm{~m})$, and 12 months (12m) after denture delivery. The acquisition time, voxel size and slice thickness were standardized for all participants. The acquired DICOMs files were stored on a compact disc. The marginal bone resorption was measured at mesial, distal, buccal and lingual surface of each implant. Using a curve tool of the software (OnDemand3DApp Software; CyberMed Inc), a curve was drawn to bisect each implant from the occlusal (axial) view. The images were reconstructed by the software. Cross sectional images for each implant and panoramic images for all implants were created. Mesial and distal peri-implant bone resorptions were measured at the panoramic images. Buccal and lingual bone resorptions were calculated at cross sectional images (fig4). Mesial, distal, buccal, and lingual bone losses were averaged and the mean was subjected to statistical analysis. Distance from implant abutment

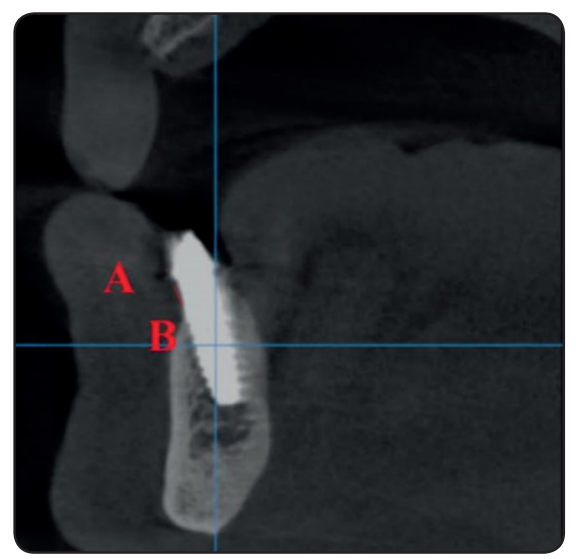

Fig (4) Measurement of bone loss using Cone beam CT junction (point A) to the bone contact with implant (point B) was measured to give bone level. Bone loss was calculated by subtracting bone levels at $6 \mathrm{~m}$ and $12 \mathrm{~m}$ from bone levels at base line. The measurements were performed on the patient level, ie, right and left measurements for canine and molar implants were averaged. To test the inter-examiner reliability, 3 different examiners performed the measurement. The readings were compared using alpha Cronbach test and the measurements were reliable if coefficient was $>.80$.

\section{Statistical analysis}

Data was analyzed with SPSS program version 22 (Statistical Packages for Social Science, SPSS Inc., Chicago, IL, USA). The data was non-parametric as verified by One-Sample Kolmogorov-Smirnov Test. Friedman test was used to compare different observation times within groups, and Wilcoxon signed ranks test was used to compare between each two times. For between-group comparisons, the non-parametric Mann- Whitney test was used. The threshold for statistical significance was set at $\mathrm{P}<.05$.

\section{RESULTS}

Two posterior implants failed in 1 patient related to milled bar group resulting in $95 \%$ survival rate this group. The survival rate in SFI bar group was $100 \%$. Failures occurred in the first 3 months after loading and failed implants were associated with mobility and suppuration. No difference in survival rate between groups was noted (Log rank test, $\mathrm{p}>.05)$. The study was conducted according to the "intention to treat principle". Therefore, the patient was excluded from further investigations and the posterior bar segments were sectioned and the overdenture was left to be retained on the other 3 implants (with 2 bar segments only) as patient denied further implant placement.

Comparison of clinical and radiographic outcomes between attachments and observations are presented in table 1. Pair-wise comparisons between 
each 2-time intervals are presented in the same table. Plaque index significantly increased with passage of time for milled bar group (there was a significant difference between each 2-time intervals). However, there was no significant difference in plaque index between time intervals for SFI group. Milled bar showed significant higher plaque scores than SFI bar groups after 6 and 12 months of prosthesis delivery. Gingival index showed no significant difference between observation times nor between groups. Pocket depth significantly increased with passage of time for milled bar group (there was a significant difference between each 2-time intervals). However, there was no significant difference in pocket depth between time intervals for SFI group. Milled bar showed significant higher pocket depth than SFI bar groups after 6 and 12 months of prosthesis delivery. Fixture stability increases with time but there was no significant difference in implant stability between time intervals nor between groups.

For milled bar group, the median peri-implant bone loss was .83 and $1.12 \mathrm{~mm}$ after 6 and 12 months respectively. For SFI bar group, the median periimplant bone loss was .52 and $.72 \mathrm{~mm}$ after 6 and 12 months respectively. Bone resorption significantly increased after 12 months compared to 6 months in both groups. Milled bar group recorded significant higher bone loss than SFI bar group after 6 and 12 months of prosthesis delivery.

TABLE (1) Comparison of clinical and radiographic outcomes between attachments and observations

\begin{tabular}{|c|c|c|c|c|}
\hline & $\begin{array}{c}\text { At time of prothesis } \\
\text { delivery (T0) }\end{array}$ & $\begin{array}{c}6 \text { months after } \\
\text { prothesis delivery(T6) }\end{array}$ & $\begin{array}{c}12 \text { months after } \\
\text { prothesis delivery (T12) }\end{array}$ & $\begin{array}{l}\text { Freidman test } \\
\quad \text { (p value) }\end{array}$ \\
\hline \multicolumn{5}{|c|}{ Plaque index } \\
\hline Milled bar group M (mi-ma) & $.5(.00-1.0)^{\mathrm{a}}$ & $1.5(1.0-2.0)^{b}$ & $2.0(1.0-3.0)^{\mathrm{c}}$ & $.002 *$ \\
\hline SFI bar group M (mi-ma) & $.5(.00-1.0)^{\mathrm{a}}$ & $.5(.00-1.0)^{\mathrm{a}}$ & $1.0(.00-1.0)^{\mathrm{a}}$ & .62 \\
\hline Mann-Whitney test (p value) & 1.00 & $.015 *$ & $.020 *$ & \\
\hline \multicolumn{5}{|c|}{ Gingival index } \\
\hline Milled bar group M (mi-ma) & $.0(.00-.5)^{\mathrm{a}}$ & $.21(.00-1.0)^{\mathrm{a}}$ & $.32(.00-1.0)^{\mathrm{a}}$ & .34 \\
\hline SFI bar group M (mi-ma) & $.0(.00-.5)^{\mathrm{a}}$ & $.4(.00-1.0)^{\mathrm{a}}$ & $.5(.00-3.0)^{\mathrm{a}}$ & .081 \\
\hline Mann-Whitney test (p value) & 1.00 & .59 & .15 & \\
\hline \multicolumn{5}{|c|}{ Pocket depth } \\
\hline Milled bar group M (mi-ma) & $.75(.25-1.5)^{\mathrm{a}}$ & $1.50(1.00-2.00)^{\mathrm{b}}$ & $.2 .5(1.5-3.0)^{\mathrm{c}}$ & $.004 *$ \\
\hline SFI bar group M (mi-ma) & $.80(.25-1.5)^{\mathrm{a}}$ & $1.00(0.5-1.5)^{\mathrm{a}}$ & $1.2(.00-1.5)^{\mathrm{a}}$ & .061 \\
\hline Mann-Whitney test (p value) & .13 & $.039 *$ & $.013^{*}$ & \\
\hline \multicolumn{5}{|c|}{ Fixture stability } \\
\hline Milled bar group M (mi-ma) & $67(65-69)^{\mathrm{a}}$ & $68(66-70)^{\mathrm{a}}$ & $69(66-70)^{\mathrm{a}}$ & .52 \\
\hline SFI bar group M (mi-ma) & $66(64-70)^{\mathrm{a}}$ & $67(65-71)^{\mathrm{a}}$ & $68(65-70)^{\mathrm{a}}$ & .81 \\
\hline Mann-Whitney test (p value) & .34 & .65 & .23 & \\
\hline \multicolumn{5}{|c|}{ Bone loss } \\
\hline Milled bar group M (mi-ma) & - & $.83(.00-1.0)^{\mathrm{a}}$ & $1.12(.9-1.3)^{\mathrm{b}}$ & $.024 *$ \\
\hline SFI bar group M (mi-ma) & - & $.52(.00-1.0)^{\mathrm{a}}$ & $.72(.51-1.0)^{\mathrm{b}}$ & $.031 *$ \\
\hline Mann-Whitney test ( $p$ value) & - & $.027 *$ & $.013 *$ & \\
\hline
\end{tabular}

M: median, mi: minimum, ma: maximum, *: p value significant at .05 . Different letters in the same raw indicate significant difference between observation times (Wilcoxon signed ranks test, $p<.05$ ). Same letters indicate no difference between time intervals (Wilcoxon signed ranks test, $p>.05$ ). 


\section{DISCUSSION}

Although SFI bar designed originally for chair side application and immediate loading of the overdentures, delayed loading (after 2 weeks of implant insertion) was utilized in this study. This was done to standerdize the loading protocol in both groups since, it was impossible to construct the milled bar and the housing (in milled bar group) on the same day of implant placement or within few days later. Manual bar milling was used instead of CAD/CAM bar milling as titanium milling machines were not available at the start of this study. In the current investigation Cone beam computerized tomography (CBCT) was used for evaluation of marginal bone resorption as it provides information on bone loss on buccal and lingual aspects of the implants as well as mesial and distal aspects due to its three-dimensional nature. In contrast, Periapical radiography are 2 dimensional only. Moreover, CBCT, can be used easily especially with elevated floor of the mouth without causing patient discomfort as periapical radiographs do. CBCT also has no magnification or distortion as panoramic radiographs ${ }^{36,37}$. The use of CBCT in measuring bone resorption around implants was recommended by other investigators ${ }^{38,39}$.

For milled bar group, one posterior implants failed resulting in $95 \%$ survival rate. This failure could be attributed to several factors. Fristly, the mandibulardeformation occurred when rigid splinted superstructures was used could be responsible for transmitting high forces to the posterior implants in the critical healing period. Secondly the deterioration of bar accuracy during casting due to increased bar length may decrease the passivity of the milled bar. Similarly, Miyamoto et al., ${ }^{40}$ showed that; insertion of implants in the posterior region of the mandible worsens the prognosis after loading of these implants. They attributed this to the deterioration of the accuracy of the superstructure, location of the posterior implants in the area of highest load, and mandibular deformation and flexture caused by actions of masticatory muscles which may endanger bone to implant interface. On the other hand SFI bar has stress free nature which maximize bar passivity without transmitting forces to the implants during screwing. Its also eliminates the effect of mandibular deformation as the bar based on joint design and not rigid. This allows mandibular flexture to occur without transmitting load to the posterior implants. Threfore, the implant survival rate of the SFI bar group was $100 \%$.

For milled bar group, plaque index increased significantly with time. Also milled bar showed significant higher plaque scores than SFI bar at 6 and 12 months. This may be due to milled bar cover large area of the peri-implant soft tissue as it has rectangular cros-section. This may cause difficulty for the patients to perform adequate cleansing under the bar. In line with this observation, Krennmair et $\mathrm{a}^{25}$ found a time-depending increase of plaque index for milled bar attachments of mandibular overdentures. Also milled bars were casted, then milled. As a result of casting process, nodules and scratches may occur $^{41}$ which may enhance plaque accumulation. In contrast, SFI bar was ready made (no casting error), so it had a smooth surface. This prefabricated smooth surface prevents plaque accumulation, and enhance self-cleaning of the bar and oral hygiene. Also, SFI bar has small circular cross section and covers a small area of mucosa which may reduce plaque accumulation and enhance accessibility for oral hygiene. In this study, however, the increased plaque scores with time did not cause a significant increase in gingival indices.

In this study, the pocket depth increased with time and milled bar group showed significant higher pocket depth than SFI bar group after 6 and 12 months. This clould be attributed to the increased peri-implant bone resorption in the milled bar group as demonestrated in the results of this study together with increased peri-implant mucosal proliferation (caused by increased plaque accumulation) which 
may increase pocket depth measurements. A similar finding was also observed in other studies ${ }^{25,42}$. There was no significant difference in stability of implants between both groups. a similar finding was observed in other studies ${ }^{43,44}$. This could be attributed to the excellent bone quantity and quality in the mandible anterior and posterior to the mental foramena which increase bone to implant contact and increase implant stability.

The amount of bone loss in both groups ranged between $.52 \mathrm{~mm}$ to $1.12 \mathrm{~mm}$ after one year which is still within the normal range of bone loss noted in the literature ${ }^{45}$. The reduced bone loss could be attributed to the splinting of the implants, wide load distribution effect of the bars and the fact that these implants are installed in the dense bone of the mandible ${ }^{39}$. This bone is associated with increased implant stability and reduced bone loss. The increased bone loss with advance of time in both groups may be attributed to the bone remodelling process as a result of surgical procedure combined with increased occlusal load as a result of early implant loading protocol used in this study.

However, milled bar showed significant higher bone loss than SFI bar at 6 and 12 months after denture insertion. Several explanations may be responsible for this finding. Most important one is the stress-free nature of the SFI bar which ensures complete screwing of the bar without transmitting micromovements to the implants. This is a crucial factor especially in the initial healing period after early loading. According to manufacturer, due to the telescopic design of the bar joints, no lateral stress is applied to the implants ${ }^{29}$. In contrast, several factors may cause inaccuracy and lack of total passive fit of the milled bar such as impression procedure, impression material, deterioration of casting by increased bar length ${ }^{46}$. This may transmit forces to the implants which may negatively affect bone loss ${ }^{47}$. Moreover, the effect of mandibular deformation and flexure was not evident with SFI bar due to the joint nature of the bar which minimizes stress transmission to the implants during mandibular deformation. On the other hand, the rigid nature of the milled bar transmits more forces especially to the posterior implant during mandibular deformation and may increase bone loss at these implants as stated previously. Furthermore, the rough surface of the milled bar and metal housings caused by casting process, finishing and polishing may enhances plaque accumulation, and bone loss. Another explanation for increased bone loss with milled bar is the total height of the bar (about $6 \mathrm{~mm}$ ) which is more than height of the SFI bar (about $3 \mathrm{~mm}$ from the mucosal level). This may cause vertical cantilever and increase stresses to the implant compared to SFI bar. Finally, SFI bar can tolerate implant divergence up to $15^{\circ}$ without transmitting stresses to the implants due to the nature of telescopic ball joint of the bar ${ }^{46}$. In contrast implant disparallism with milled bar may increase friction of prosthetic screw during screwing the bar to the abutments and may increase implant micromotions with non-parallel implants.

The limitations of this study include, the small sample size, the short follow up interval, and the lack of comparison between anterior and posterior implants. Therefore, randomized controlled trials with increased patient sample and longer follow up period are needed to ensure the finding of the present investigation and to compare other clinical outcomes as patient satisfaction, chewing efficiency and muscle activity between types of tested attachments.

\section{CONCLUSION}

Within the limitation of this randomized trial, it could be concluded that SFI bar is more advantageous for early loaded 4 implants supporting mandibular overdentures than milled bar as it was associated with decreased plaque accumulation, pocket depth and marginal bone resorption after one year. 


\section{REFERENCES}

1. Abd El-Dayem MA, Assad AS, Abdel-Ghany MM. The effect of different mandibular dentures on antagonistic maxillary ridge. Implant Dent. 2007;16:421-9.

2. Cordaro L, di Torresanto VM, Petricevic N, Jornet PR, Torsello F. Single unit attachments improve peri-implant soft tissue conditions in mandibular overdentures supported by four implants. Clin Oral Implants Res. 2013;24:536-42.

3. de Jong MH, Wright PS, Meijer HJ, Tymstra N. Posterior mandibular residual ridge resorption in patients with overdentures supported by two or four endosseous implants in a 10-year prospective comparative study. Int J Oral Maxillofac Implants. 2010;25:1168-74.

4. Krennmair G, Krainhofner M, Piehslinger E. The influence of bar design (round versus milled bar) on prosthodontic maintenance of mandibular overdentures supported by 4 implants: a 5-year prospective study. Int J Prosthodont. 2008;21:514-20.

5. Elsyad MA, Hegazy SA, Hammouda NI, Al-Tonbary GY, Habib AA. Chewing efficiency and electromyographic activity of masseter muscle with three designs of implantsupported mandibular overdentures. A cross-over study. Clin Oral Implants Res. 2014;25:742-8.

6. Martinez-Lage-Azorin JF, Segura-Andres G, Faus-Lopez J, Agustin-Panadero R. Rehabilitation with implant-supported overdentures in total edentulous patients: A review. J Clin Exp Dent. 2013;5:e267-72.

7. Batenburg RH, Meijer HJ, Raghoebar GM, Van Oort RP, Boering G. Mandibular overdentures supported by two Branemark, IMZ or ITI implants. A prospective comparative preliminary study: one-year results. Clin Oral Implants Res. 1998;9:374-83.

8. Sertgoz A, Guvener S. Finite element analysis of the effect of cantilever and implant length on stress distribution in an implant-supported fixed prosthesis. J Prosthet Dent. 1996;76:165-9.

9. Sadowsky SJ, Caputo AA. Effect of anchorage systems and extension base contact on load transfer with mandibular implant-retained overdentures. J Prosthet Dent. 2000;84:327-34

10. Katsoulis J, Walchli J, Kobel S, Gholami H, MericskeStern R. Complications with computer-aided designed/ computer-assisted manufactured titanium and soldered gold bars for mandibular implant-overdentures: short-term observations. Clin Implant Dent Relat Res. 2015;17 Suppl 1:e75-85

11. Misch CE. Treatment Options for Mandibular Implant Overdentures in: Misch CE, Bidez MW, Judy KWM et al, eds Dental implant prosthetics. 3nd ed St Louis: Mosby. 2005:218-35.

12. Caruso G, Cattaneo A. Removable prosthesis supported by implants according to the Cagliari modified conometry technique: case report. Int J Periodontics Restorative Dent. 2007;27:259-65

13. Kaufmann R, Friedli M, Hug S, Mericske-Stern R. Removable dentures with implant support in strategic positions followed for up to 8 years. Int J Prosthodont. 2009;22:23341; discussion 42 .

14. Krennmair G, Krainhofner M, Piehslinger E. Implantsupported mandibular overdentures retained with a milled bar: a retrospective study. Int J Oral Maxillofac Implants. 2007;22:987-94

15. Moll D, Yildirim M, Spiekermann H, Wolfart S. Telescopic crown-retained removable partial dentures on teeth and implants: An 8- to 9-year prospective randomized clinical trial. Clin Oral Implants Res. 2012.

16. Shaarawy MA, Aboelross EM. The effect of varying implant position in immediately loaded implant-supported mandibular overdentures. J Oral Implantol. 2013; 39:345-54.

17. Misch CE, Wang H-L, Misch CM, Sharawy M, Lemons J, Judy KW. Rationale for the application of immediate load in implant dentistry: Part I. Implant Dent. 2004;13:207-17.

18. Chiapasco M, Gatti C. Implant-retained mandibular overdentures with immediate loading: a 3- to 8-year prospective study on 328 implants. Clin Implant Dent Relat Res. 2003;5:29-38.

19. Mericske-Stern R, Piotti M, Sirtes G. 3-D in vivo force measurements on mandibular implants supporting overdentures. A comparative study. Clin Oral Implants Res. 1996;7:387-96.

20. Misch CE, Wang HL, Misch CM, Sharawy M, Lemons J, Judy KW. Rationale for the application of immediate load in implant dentistry: part II. Implant Dent. 2004; $13: 310-21$.

21. Spiekermann H. Implantology. In: Rateitschak, K.H. \& Wolf, H.F., eds. Color Atlas of Dental Medicine. New York: Thieme Medical Publishers. 1995:164. 
22. Barbi FC, Camarini ET, Silva RS, Endo EH, Pereira JR. Comparative analysis of different joining techniques to improve the passive fit of cobalt-chromium superstructures. J Prosthet Dent. 2012;108:377-85.

23. Ahuja S, Cagna DR. Defining available restorative space for implant overdentures. J Prosthet Dent. 2010;104:133-6.

24. Efvinol. B, Jorgeusen. D. Prosthetic for elderly. Quintessence, Publication Co. Inc.Chicago. . 1999:P233.

25. Krennmair G, Suto D, Seemann R, Piehslinger E. Removable four implant-supported mandibular overdentures rigidly retained with telescopic crowns or milled bars: a 3-year prospective study. Clin Oral Implants Res. 2012;23:481-8.

26. Tipton PA. The Milled Bar-Retained Removable Bridge Implant-Supported Prosthesis: A Treatment Alternative for the Edentulous Maxilla. Journal of Esthetic and Restorative Dentistry. 2002;14:208-16.

27. Kim HY, Kim RJ, Qadeer S, Jeong CM, Shin SW, Huh JB. Immediate loading on mandibular edentulous patient with SFI Bar(R) overdenture. J Adv Prosthodont. 2011;3:47-50.

28. Wei L, Ma Q, Qin X, Pan S. In Vitro Cyclic Dislodging Test on Retentive Force of Two Types of Female Parts of SFI-Bar. The International journal of prosthodontics. 2016;29:293-5.

29. Ha SR, Kim SH, Song SI, Hong ST, Kim GY. Implantsupported overdenture with prefabricated bar attachment system in mandibular edentulous patient. J Adv Prosthodont. 2012;4:254-8.

30. Kobayashi M, Srinivasan M, Ammann P, Perriard J, Ohkubo C, Muller F, et al. Effects of in vitro cyclic dislodging on retentive force and removal torque of three overdenture attachment systems. Clin Oral Implants Res. 2014; 25:426-34.

31. Sannino G, Bollero P, Barlattani A, Gherlone E. A Retrospective 2-Year Clinical Study of Immediate Prosthetic Rehabilitation of Edentulous Jaws with Four Implants and Prefabricated Bars. J Prosthodont. 2017; 26:387-94.

32. Mombelli A, van Oosten MA, Schurch E, Jr., Land NP. The microbiota associated with successful or failing osseointegrated titanium implants. Oral Microbiol Immunol. 1987;2:145-51.

33. Loe H, Silness J. Periodontal Disease in Pregnancy. I. Prevalence and Severity. Acta Odontol Scand. 1963; 21:533-51.
34. Meredith N, Alleyne D, Cawley P. Quantitative determination of the stability of the implant-tissue interface using resonance frequency analysis. Clin Oral Implants Res. 1996;7:261-7.

35. Glauser R, Sennerby L, Meredith N, Ree A, Lundgren A, Gottlow J, et al. Resonance frequency analysis of implants subjected to immediate or early functional occlusal loading. Successful vs. failing implants. Clin Oral Implants Res. 2004;15:428-34.

36. Naitoh M, Hayashi H, Tsukamoto N, Ariji E. Labial bone assessment surrounding dental implant using cone-beam computed tomography: an in vitro study. Clin Oral Implants Res. 2012;23:970-4.

37. Raes F, Renckens L, Aps J, Cosyn J, De Bruyn H. Reliability of circumferential bone level assessment around single implants in healed ridges and extraction sockets using cone beam CT. Clin Implant Dent Relat Res. 2013;15:661-72.

38. Razavi T, Palmer RM, Davies J, Wilson R, Palmer PJ. Accuracy of measuring the cortical bone thickness adjacent to dental implants using cone beam computed tomography. Clin Oral Implants Res. 2010;21:718-25.

39. Elsyad MA, Khirallah AS. Circumferential bone loss around splinted and nonsplinted immediately loaded implants retaining mandibular overdentures: A randomized controlled clinical trial using cone beam computed tomography. J Prosthet Dent. 2016;116 741-8

40. Miyamoto Y, Fujisawa K, Takechi M, Momota Y, Yuasa $\mathrm{T}$, Tatehara S, et al. Effect of the additional installation of implants in the posterior region on the prognosis of treatment in the edentulous mandibular jaw. Clin Oral Implants Res. 2003;14:727-33.

41. ELsyad MA, Soliman TA, Khalifa AK. Retention and Stability of Rigid Telescopic and Milled Bar Attachments for Implant-Supported Maxillary Overdentures: An In Vitro Study. Int J Oral Maxillofac Implants. 2018;33:e127-e33.

42. Zou D, Wu Y, Huang W, Wang F, Wang S, Zhang Z, et al. A 3-year prospective clinical study of telescopic crown, bar, and locator attachments for removable four implantsupported maxillary overdentures. Int $\mathrm{J}$ Prosthodont. 2013;26:566-73.

43. Elsyad MA, Elsaih EA, Khairallah AS. Marginal bone resorption around immediate and delayed loaded implants supporting a locator-retained mandibular overdenture. A 1-year randomised controlled trial. J Oral Rehabil. 2014;41:608-18. 
44. Alsabeeha NH, Payne AG, De Silva RK, Thomson WM. Mandibular single-implant overdentures: preliminary results of a randomised-control trial on early loading with different implant diameters and attachment systems. Clin Oral Implants Res. 2011;22:330-7.

45. Albrektsson T, Zarb G, Worthington P, Eriksson AR. The long-term efficacy of currently used dental implants: a review and proposed criteria of success. Int $\mathrm{J}$ Oral Maxillofac Implants. 1986;1:11-25.
46. Albrecht D, Ramierez A, Kremer U, Katsoulis J, MericskeStern R, Enkling N. Space requirement of a prefabricated bar on two interforaminal implants: a prospective clinical study. Clin Oral Implants Res. 2015;26:143-8.

47. Moy PK, Medina D, Shetty V, Aghaloo TL. Dental implant failure rates and associated risk factors. The International journal of oral \& maxillofacial implants. 2005;20: 569-77. 